\title{
Chemotherapy in the elderly - How intense should treatment be?
}

\author{
Axel R. Zander', René J. Hornung ${ }^{2}$, Hans-Peter Lipp ${ }^{3}$
}

Research Department Cell and Gene Therapy, Clinic for Stem Cell Transplantation, University Medical Centre Hamburg-Eppendorf, Hamburg, Germany ${ }^{1}$

University Medical Centre Hamburg-Eppendorf, Hamburg, Germany²

Department of Hospital Pharmacy, University Tübingen, Tübingen, Germany ${ }^{3}$

Prof. Dr. Axel R. Zander,

Strandweg 10, 23570 Lübeck Germany
Phone: +49-40-42803-4850/51

Fax: $\quad+49-40-42803-3795$

E-mail: arzzander@aol.de

\section{Summary}

Physiological changes and deficiencies in cognitive processes in the elderly have an influence on therapy and drug dosage compliance. The consequences of differences for the outcome of especially chemotherapies are neither well nor systematically studied. Existing studies though could actually demonstrate age-related differences in clinical pharmacokinetics. Another problem is the increased number of prescribed drugs that are often necessary when getting older (polypharmacy) and their interference with over-the-counter drugs (OTC) and complementary and alternative medicine (CAM). While they are often seen as harmless since they require no prescription or are of "natural origin", they can contain pharmaceutical active agents. For example green tea is reported to prevent prostate cancer and pre-menopausal breast cancer and is therefore often recommended to cancer patients, but also contains Epigallocatechin gallate (EGCg) an active substance which decreases the bio-availability of the anti-cancer drugs Bortezomid or Sunitinib. Conclusion: a further and more systematic study of age-related differences in the outcome of chemotherapies in the elderly is necessary. Here especially the kidney function requires adaption of treatment regimen. Furthermore the interactions with other drugs, in particular over-thecounter and alternative medicine, need to be better understood and communicated.

\section{Keywords}

hematopoietic stem cell transplantation, chemotherapy, drug interference, clinical outcomes, age dependence, complementary medicine.

\section{Introduction}

Little is known about cancer chemotherapy in the elderly. There are only a few studies which include patients with cancer who at the same time are older than seventy years of age. It is a common practice to treat elderly patients according to existing protocols for younger patients with reduced doses and off the record; the data are not collected and analyzed. Outcome of the chemotherapy in the elderly is influenced by age-related changes in body composition and normal organ function as well as age related deficiencies in cognitive processes. Reduced visual performance and reduced manual dexterity in the elderly lead frequently to dosing and compliance errors. Another complicating factor is the increasing use of complementary and alternative medicines by elderly patients. This article will review the age related changes of body function, organ toxicity after chemotherapy in the elderly and the potential impact of complementary and alternative medicines. 
Defining old is a complex process. The age of 60 or 65 , roughly equivalent to the age of retirement in most Western countries, is said to be the beginning of old age. The aging process is of course a biological reality with its own dynamic largely beyond individual control. In view of the increasing age of the population in industrialized countries, a differentiation by age (61-75 years: elderly persons; $76-90$ years of age: old persons; above 90 years: very old persons) seems to be useful.

There are age-related changes in body composition such as increased body fat that amounts to circa $35 \%$ at age 75 , reduction of total body water that amounts to about $17 \%$ at age 60 , and decrease in extracellular liquid, to circa $40 \%$ at age 65. Aside from changes in body composition, there is a reduction of normal organ function every year: cardiac output, by about $1 \%$; liver size, by $2 \%$; liver blood flow, $1 \%$; kidney blood flow, by $1 \%$; tubular function, by $1 \%$, and glomerular filtration rate (GFR), by $1 \mathrm{ml} / \mathrm{min} / 1,73 \mathrm{~m}^{2}$.

Changes in biological functions in old age lead to consequences for pharmacotherapy. Reduced secretion of gastric acid and gastrointestinal tract motility might lead to a reduction of bioavailability of certain drugs. Increased body fat might change the distribution volume of lipophilic drugs. Reduction of albumin concentration might lead to an increase of non-albumin bound drugs. Reduction of GFR and tubular secretional function might lead to an accumulation of renally eliminated active substances.

Other age related deficiencies might complicate effective chemotherapy in old and very old patients. Reduced mobility and increased risk of osteoporosis increase the risk and the frequency of falls. Impairment of short-term memory leads to dosing errors and compliance problems and an increased belief in "tonics", which might lead to drug interactions. Functional deficiencies, including emotional changes reduce the ability for directed and efficient actions and might lead to lethargy and non-adherence to treatment schedules. Reduced visual performance and reduced manual dexterity might lead to orientation problems, dosage errors and manual difficulties with splitting of tablets.
Polypharmacotherapy leads to particular problems in the elderly patient population. According to one study, the PRISCUS Project, every health insured older patient is prescribed 3.6 drugs on the average. Over-the-counter (OTC) products are added to this number. $25 \%$ of the prescribed drugs are potentially inadequate medications. [1]

The problem of non-compliance is already evident in twice daily (bid) vs. once daily (qd) dosing of medications. Published data on other twice daily medications (eg. metformine, glipizide, metoprolol) show that adequate adherence (defined as greater than $80 \%$ of pills taken) may be only $52-65 \%$ [11]. A Polish study comparing beta-blockers given once daily (betaxolol) or twice daily (metoprolol) to patients with stable angina pectoris showed $58.6 \%$ vs. $42.0 \%$ for doses taken in the correct time window and $77.4 \%$ vs. $53.1 \%$ for correct interdose intervals in favor of the drug taken once daily [8].

Hamaker et al. [6] state that currently ongoing trials in hematological malignancies are unlikely to significantly improve our knowledge of the optimal treatment of older patients, as those outcome measures, that are of primary importance to this patient population are still included in only a minority of studies. A broader database of chemotherapy data in elderly patients is needed to enable the oncologist to deliver evidence based and patient focused cancer care.

The experience with chemotherapeutic agents and their pharmacokinetics in patients with old age is limited. Hurria and Lichtman [7] analyze clinical pharmacology of cancer therapies in older patients in a mini review. In 18 studies older and younger patient groups were compared. When treated with Paclitaxel (3 studies), Docetaxel (4 studies), Oxaliplatin (1 study), Temozolomide (1 study), Vinorelbine (2 studies), 5- Fluorouracil (1 study), Capecitabine (1 study), Etoposide (3 studies), Doxorubicin (2 studies) only 5/18 studies could actually demonstrate age-related differences in clinical pharmacokinetics, but this remains controversial.

The International Society of Geriatric Oncology (SIOG) arrived at the following recommendations (Table 1) for the adjustment of dosing in elderly patients, according to the underlying renal function but also including clinical experience [10].

\begin{tabular}{|l|l|l|l|}
\hline INN & $90-60 \mathrm{ml} / \mathrm{min}$ & $60-30 \mathrm{ml} / \mathrm{min}$ & $30-15 \mathrm{ml} / \mathrm{min}$ \\
\hline Melphalan & $100-200 \mathrm{mg} / \mathrm{m}^{2}$ & $75 \%$ & $50 \%$ \\
\hline Oxaliplatine & $85-100 \mathrm{mg} / \mathrm{m}^{2}$ & $100 \%$ & $100 \%$ \\
\hline Fludarabine & $25 \mathrm{mg} / \mathrm{m}^{2}$ & $20 \mathrm{mg} / \mathrm{m}^{2}$ & $15 \mathrm{mg} / \mathrm{m}^{2}$ \\
\hline Capecitabine & $1250 \mathrm{mg} / \mathrm{m}^{2}$ every $12 \mathrm{~h}$ & $950 \mathrm{mg} / \mathrm{m}^{2}$ every $12 \mathrm{~h}$ & Contraindicated \\
\hline
\end{tabular}

Table 1: Dosing adjustment in elderly cancer patients. Recommendations of the International Society of Geriatric Oncology (SIOG) according to the underlying renal function [10] 
Kintzel and Dorr [9] recommended dose modification for another set of antineoplastic drugs for patients with renal dysfunction (Table 2). The dose modification is clearly related to the fraction of renally excreted active or toxic moiety of the drug. Etoposide with a fraction of $32 \%$ requires nearly no reduction in patients with a creatinine clearance of $30 \mathrm{ml} /$ min., whereas methotrexate with a fraction of $77 \%$ of renally excreted or toxic moiety requires a reduction of $50 \%$ in patients with INN of $45 \mathrm{ml} / \mathrm{min}$. and should not be given to patients with lower renal functions.

\begin{tabular}{|l|l|l|l|l|}
\hline INN & $\mathrm{f}$ & $60 \mathrm{ml} / \mathrm{min}$ & $45 \mathrm{ml} / \mathrm{min}$ & $30 \mathrm{ml} / \mathrm{min}$ \\
\hline Etoposide & $32 \%$ & 0.85 & 0.80 & 0.75 \\
\hline Hydroxyurea & $36 \%$ & 0.85 & 0.80 & 0.75 \\
\hline Dacarbazine & $41 \%$ & 0.80 & 0.75 & 0.70 \\
\hline Fludarabine & $44 \%$ & 0.80 & 0.75 & 0.65 \\
\hline Lomustine (CCNU) & $50 \%$ & 0.75 & 0.70 & - \\
\hline Bleomycine & $62 \%$ & 0.70 & 0.60 & - \\
\hline HD-AraC, MTX & $77 \%$ & 0.65 & 0.50 & - \\
\hline
\end{tabular}

Table 2. Dose modification for antineoplastic drugs in renal dysfunction [9]

Decreased organ functions, besides renal clearance that may lead to consequences for pharmacotherapy, are heart function, with a reduction of myocytes and reduction of dromotrophy, eventually: left ventricular ejection function (LVEF) that may lead to congestive heart failure and cardiac arrhythmias. Regarding the nervous system, co-morbidities, such as Diabetes Mellitus may lead to higher risk for sensory neuropathies. Reduced vital and diffusion capacity of the lung may lead to higher risk for lung toxic side-affects. The reduction of bone marrow reserve may lead to severe cytopenias.
An increase in fibrinogen concentration may lead to a higher risk for venous thromboembolism.

An older study from von Hoff et al. [12] compares cumulative doses of Doxorubicin on incidence of cardiotoxicity in patients aged 40-59 vs. in patients older than 60 years of age. There was an increase in cardiotoxicity with all dose ranges in the older patient group. This difference was seen in the groups that received Doxorubicin every seven days as well as in the group that received the drug every three weeks.

\begin{tabular}{|l|l|l|l|l|}
\hline Cumulative dose $\left(\mathrm{mg} / \mathrm{m}^{2}\right)$ & $\begin{array}{l}\mathrm{q} 7 \mathrm{~d} \\
40-59 y\end{array}$ & $\begin{array}{l}\mathrm{q} 7 \mathrm{~d} \\
>60 \mathrm{y}\end{array}$ & $\begin{array}{l}\mathrm{q} 3 \mathrm{w} \\
40-59 \mathrm{y}\end{array}$ & $\begin{array}{l}\mathrm{q} 3 \mathrm{w} \\
>60 \mathrm{y}\end{array}$ \\
\hline 300 & 0.6 & 0.9 & 2.2 & 3.4 \\
\hline 400 & 0.7 & 1.2 & 2.3 & 4.6 \\
\hline 500 & 1.5 & 2.3 & 5.8 & 8.9 \\
\hline 600 & 3.9 & 6.1 & 14.9 & 22.4 \\
\hline 700 & 8.7 & 13.2 & 30.5 & 43.5 \\
\hline
\end{tabular}

Table 3: Doxorubicin-induced cardiotoxicity (\%) related to cumulative dose. Modified from [12].

Newer orally available "targeted" anti-cancer agents are of special interest in the elderly patient group. E.c., target protein produced by bcr-abl fusion gene can be attacked by Imatinib (GLIVEC), Dasatinib (SPRYCEL), Nilotinib (TASIGNA), Bosutinib (BOSULIF), and Ponatinib (ICLUSIG). The epidermal growth factor receptor (EGFR) is target for several drugs like Erlotinib (TARCEVA), Imatinib (GLIVEC), Afatinib (GILOTRIF), and Lapatinib (TYVERB). Other drugs like Sorafenib (NEXAVAR) and Sunitinib (SUTENT) interfere with Vascular Endothelial Growth Factor (VEGF). Other drugs like Vemurafenib (ZELBORAF) and Dabrafenib (TAFINLAR) interfere with mutations of BRAF, the serine/ threonine-protein kinase. Other targeted therapies include Crizotinib (XALKORI), Everolimus (AFINITOR), Vismodegib (ERIVEDGE), Trametinib (MEKINIST), and Ibrutinib (IMBRUVICA) as well as Thalidomide, Lenalidomide (REVLIMID), and Pomalidomide (IMNOVID) which in partly modulate the immune system. 
Particular attention needs to be directed toward the toxicity of targeted anti-cancer therapy in the elderly [5]. The older human population compared to the younger population shows more toxicity in several areas. Imatinib shows more hematologic and non-hematologic toxicities in older patients. Bevacizumab shows more thromboembolism, more fatigue and more asthenia. Bortezomib shows more gastrointestinal problems, fatigue and neuropathies. Thalidomide shows more deeper vein thrombosis. Lenalidomide needed to be discontinued more frequently in the older population related to hematological and non-hematological toxicities. No age related differences in toxicity were seen in Trastuzumab.

A well-known example for influencing therapeutically needed drug levels are the Calcineurin inhibitors (CNI). Drugs which inhibit the Cytochrome P450 3A4 enzyme system that metabolizes CNIs lead to an increased risk for toxicity, drugs which induce enzymes catabolizing CNIs lead to a decreased drug concentrations and therefore an increased risk of treatment failure. Therefore, close attention needs to be given to the drug concentration, particularly if other drugs are given which induce or inhibit enzymes.

A particular problem of drug interference constitutes overthe-counter (OTC) and complementary and alternative medicine (CAM). There are many-fold explanations:

- OTCs require no prescription, "therefore they cannot be dangerous".

- There is a need to address personal fears and worries

- Desire to do something for one's health

- Therapy considered to be harmless (natural)

- Belief: "natural" things are good

- Can do no harm
- Strengthen the immune system

- Intriguing and useful information from friends, fellow sufferers and the Internet.

Complementary and alternative medicine are based on mysticism and magic:

Mysticism (nature is benign and curing negative damaging effects are ignored); Magic (delusions and wishful thinking attempt to influence processes outside one's control).

There are only a few interactions between prescription drugs and CAM known and reported. One example is the interaction between Imatinib/St. John's Wort (hypericum perforatum), a Cyp3A-inductor. Frye et al. [3] reported an increase of Imatinib-clearance by $43 \%$ through the effect of concomitantly given St. John's Wort.

Another publication points to probable interaction of etoposide with Echinacea [2]. In this case, it was likely that Echinacea contributed to a patient's profound life-threatening thrombocytopenia and therefore should be avoided in patients receiving etoposide and possible other chemotherapeutic drugs that are CYP $3 \mathrm{~A} 4$ substrates.

Green Tea is widely used as a CAM. It has been reported in the treatment of patients with asymptomatic CLL, has been reported to induce cell death in AML, has been reported to prevent prostate cancer and pre-menopausal breast cancer. On the other hand, one of the active agents of green tea, the Epigallocatechin gallate (EGCG) decreases the bio-availability of Bortezomid, one of the most active agents in the treatment of multiple myeloma [4].

\begin{tabular}{|c|c|c|}
\hline Phytopharmaca & Active substance & Possible pharmacokintetic interaction \\
\hline $\begin{array}{l}\text { Cranberry fruit } \\
\text { (Vaccinium macrocarpon) }\end{array}$ & Anthocyane, Flavonoide & Cyp (1A2, 2C9, 3A4)- and PgP-inhibition \\
\hline $\begin{array}{l}\text { Garlic } \\
\text { (Allium sativum) }\end{array}$ & Allicin, & Cyp3A- and PgP-induktion, Cyp2C9, 2C19, 2El-inhibition \\
\hline $\begin{array}{l}\text { Ginkgo } \\
\text { (Ginkgo biloba) }\end{array}$ & Ginkgolide, Flavonoide & Cyp3A- induction, free radical scavenger properties; PD: TAH \\
\hline $\begin{array}{l}\text { Ginseng } \\
\text { (Panax ginseng) }\end{array}$ & Ginsenoside & Cyp3A-induction (\& inhibition) \\
\hline $\begin{array}{l}\text { Green tea } \\
\text { (Camellia sinensis) }\end{array}$ & Catechine (ECG, EGCG) & $\begin{array}{l}\text { Cyp3A, 2A6, 2C19, 2E1-Inhibition, increased Cyp1A2, 2B and } \\
\text { NDAPH-Cyp450-reduktase-activity, PgP-inhibition, inhibits } \\
\text { SULT1A1, SULT1A3 and 0ATP1A2, 0AT1B1, 0ATP2B1-transport, } \\
\text { stimulates 0ATP1B3-transport }\end{array}$ \\
\hline $\begin{array}{l}\text { St John's wort } \\
\text { (Hypericum perforatum) }\end{array}$ & Hyperforin, Hypericin et al. & Broad spectrum of Cyp- and $\mathrm{Pg}$ P-induction \\
\hline
\end{tabular}

Table 4: Possible pharmacokinetic interaction of phytopharmaca with prescription drugs. 


\section{Conclusions}

What needs to be generally considered regarding tumor therapy in older patients?

Many PK-studies in geriatric patients are contradictory, the problem being: small patient numbers, co-factors, analytical methods (standardization),

Especially, the kidney function is age-related and requires adherence to the treatment guides (e.g. SIOG),

Age-related co-morbidities and toxicity profiles of the involved active substances need to be correlated,

Polypharmacy (OTC) can create complex interactions in older patients. The medical history of an oncology patient should include his prescription drugs as well as the complimentary and alternative medicines.

More attention needs to be directed toward investigating these interactions. Education of patients, relatives and supportive staff is critical to achieve this.

There is a definite need for drug studies in elderly patients. It would be a first step if a means could be found to collect data from patients above the age cut-off of oncology studies when they are treated according to the protocol with or without "age adjustment" of drug doses. A second step may be the inclusion of elderly patients by increasing the age limit of the studies, and by designing specific chemotherapy studies for old patients in need of treatment.

\section{Conflict of interest}

All authors have no conflict of interest to declare.

\section{References}

1. Amann U, Schmidt N, Garbe E. Prescribing of potentially inappropriate medications for the elderly: an analysis based on the PRISCUS list. Dtsch Arztebl Int 2012; 109(5): 69-75.
2. Bossaer JB, Odle BL. Probable etoposide interaction with Echinacea. J Diet Suppl 2012;9(2): 90-5.

3. Frye RF, Fitzgerald SM, Lagattuta TF, Hruska MW, Egorin MJ. Effect of St John's wort on imatinib mesylate pharmacokinetics. Clin Pharmacol Ther 2004; 76(4): 323-9.

4. Golden EB, Lam PY, Kardosh A, Gaffney KJ, Cadenas E, Louie SG, Petasis NA, Chen TC, Schönthal AH. Green tea polyphenols block the anticancer effects of bortezomib and other boronic acid-based proteasome inhibitors. Blood 2009; 113(23): 5927-37.

5. Gonsalves W, Ganti AK. Targeted anti-cancer therapy in the elderly. Crit Rev Oncol Hematol 2011; 78(3): 227-42.

6. Hamaker ME, Stauder R, van Munster BC. Ongoing clinical trials for elderly patients with a hematological malignancy: are we addressing the right end points? Ann Oncol 2014; 25(3): 675-81.

7. Hurria A, Lichtman SM. Clinical pharmacology of cancer therapies in older adults. Br J Cancer 2008; 98(3): 517-22.

8. Kardas P. Compliance, clinical outcome, and quality of life of patients with stable angina pectoris receiving once-daily betaxolol versus twice daily metoprolol: a randomized controlled trial. Vasc Health Risk Manag 2007; 3(2): 235-42.

9. Kintzel PE, Dorr RT. Anticancer drug renal toxicity and elimination: dosing guidelines for altered renal function. Cancer Treatm Rev 1995; 21(1): 33-64.

10. Lichtman SM, Wildiers H, Launay-Vacher V, Steer C, Chatelut E, Aapro M. International Society of Geriatric Oncology (SIOG) recommendations for the adjustment of dosing in elderly cancer patients with renal insufficiency. Eur J Cancer 2007; 43(1): 14-34.

11. Tu W, Morris AB, Li J et al. Association between adherence measurements of metoprolol and health care utilization in older patients with heart failure. Clin Pharmacol Ther 2005; 77(3): 189-201.

12. Von Hoff DD, Layard MW, Basa P, Davis HL, Jr, Von Hoff AL, Rozencweig M, Muggia FM. Risk factors for doxorubicin-induced congestive heart failure. Ann Intern Med 1979; 91(5): 710-7. 